\title{
FAT DISSOCIATION IN CATTLE AND SHEEP.
}

\author{
By J. Burton Clelland, M.D., Ch.M. (Syd.), Principal Assistant \\ Microbiologist, and G. P. DARNELL-Smith, B.Sc. (Lond.), F.I.C., \\ Assistant Microbiologist. \\ (From the Government Bureau of Microbiology, Sydney, New \\ South Wales.)
}

EXTENSIVE, whitish, opaque, granular-looking masses are of not infrequent occurrence in the fat usually present around the kidney and in the mesentery and omentum of bovines in Australia. Rarely, similar but smaller areas have been seen in sheep. In cattle these areas may be single and an inch or more in diameter, or there may be several smaller ones, or they may be multiple. They seem usually located towards the centre of the fat involved, and a varying degree of fibrosis and puckering surrounds them.

These areas have a naked-eye appearance similar to the fatnecrosis, better termed fat dissociation, so frequent after severe pancreatic lesions in man, and attributed, undoubtedly correctly in these cases, to the fat-splitting ferment of the pancreatic juice set free by a pathological process in that organ. In cattle they are, however, much more extensive in area, and no disease of the pancreas has been noticed in association with them.

Frozen sections, examined under the microscope, show that most of the fat cells in the affected area fail to take up Sudan III., and that they are occupied by fine radiating bundles of crystals. Around the affected area is a varying degree of fibrosis, with rounded or elongated connective tissue cells.

By steeping thin slices of the areas in a 2 per cent. solution of copper acetate more or less of the crystalline areas take on a bright bluish-green colour, due to the formation of coloured fattyacid salts of copper.

This condition is therefore unquestionably that of a dissociation of the fat stored up in the fat cells, with the liberation of glycerine, and a deposit in the cells of the insoluble fatty acids.

The question arises, What is the exact nature of the process by which this result is brought about? It is evidently not due to the action of any fat-splitting pancreatic ferment. Is it due to a reversal of the process by which the fat was originally synthesised and stored in the fat cells? The consideration of this question involves discussion of the way in which fat becomes stored in the adipose tissue cells of the body.

In this connection the following epitome of previous work on fats and their storage in the animal body may help us to understand the possible forces at work in the process of tat decomposition under consideration.

The origin of fats in the animal body is threefold-one portion is derived from the fats which have been ingested as food; another is formed from the carbohydrates; while a third portion results from the decomposition of albumins. Cattle which are fed on nitrogenous food exclusively do not fatten, or only to a slight extent, whereas 
they soon gain in weight when a certain proportion of carbohydrate is added to their food; hence we may regard the greater part of the fat of bovines as having been derived primarily from carbohydrates. Magnus Levy ${ }^{1}$ found among the acids formed in the liver, when portions of this organ were kept aseptically in a thermostat for some days, acetic, lactic, and butyric; hydrogen also was given off. He adopts as the explanation of the appearance of the butyric acid a hypothesis originally put forward by Nencki. That is, that in the first instance lactic acid is formed from the sugar; that lactic acid readily splits into formic acid and the aldehyde with one less carbon atom than the hydroxy acid, in the case of lactic acid acetic aldehyde; that the aldehyde then condenses to form aldol, which is

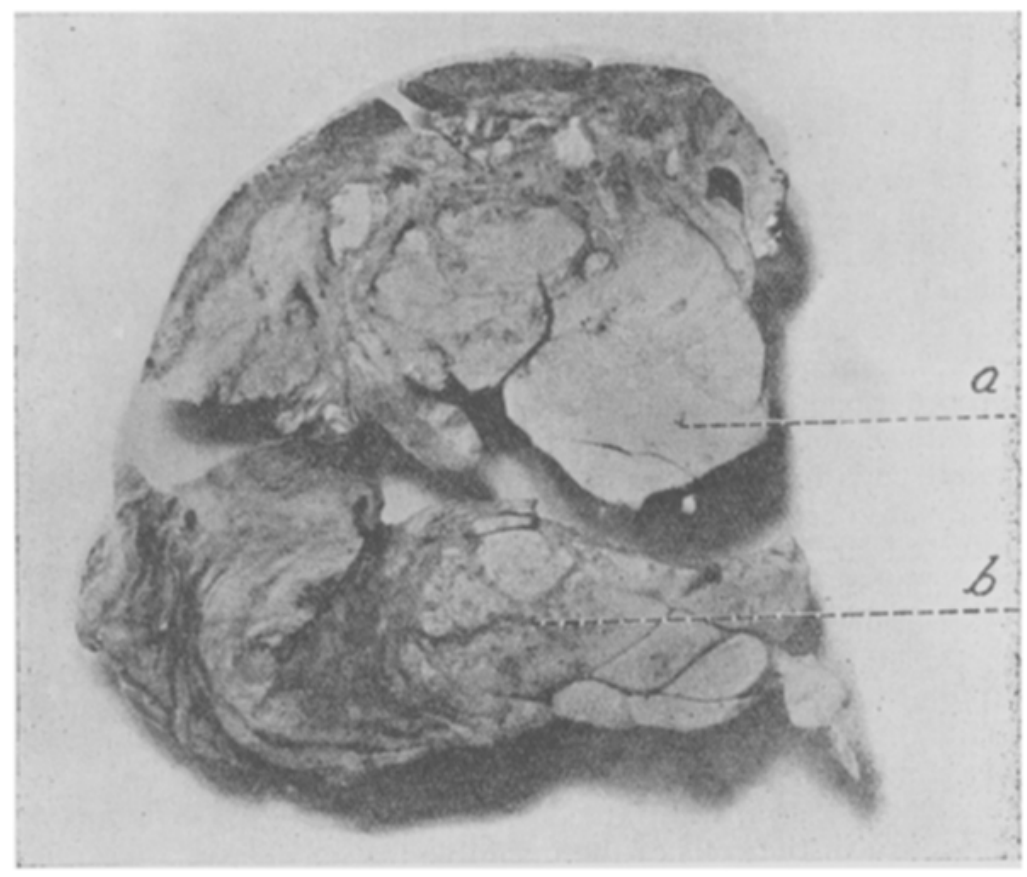

FIG. 1.

Photograph of peri-renal fat from bovine, showing extensive areas of fat dissociation. The specimen has been steeped in copper acetate solution.

(a) Large opaque whitish area of fat dissociation surrounded by slight fibrosis and unaffected fatty tissue; $(b)$ the darker spots in this area of fat dissociation represent bluish-green masses of fatty acid salts of copper.

the $\mathrm{B}$ oxybutyric aldehyde, from which it is easily conceivable that butyric acid may be formed.

Possibly the synthesis of fats from carbohydrates may, in the bodies of bovines, take place along similar lines.

Concerning lipase, the fat-splitting enzyme of the pancreas, the following facts have been established. "Under normal conditions the lipase of the pancreatic juice causes the cleavage of fats into 


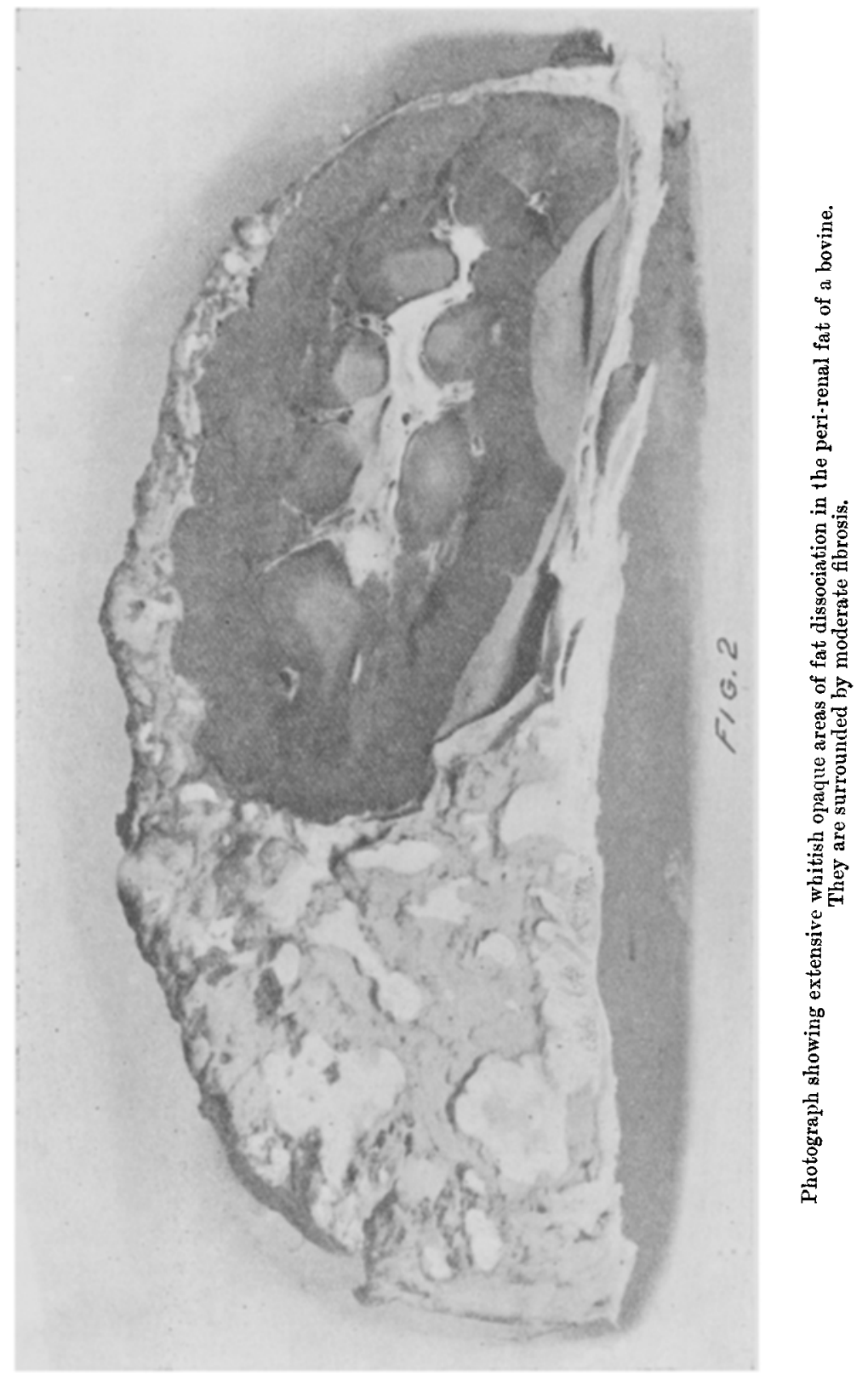


glycerine and fatty acids, which are then absorbed and reconstructed into neutral fats by the intracellular lipase, in consequence of the reversible action of which this is capable" (Kastle and Lowenhart). ${ }^{1}$

Hanriot 2 prepared lipase from the serum and from the pancreas of a dog, and it appears from his experiments that serum lipase is more energetic than pancreatic lipase in the presence of the products of the reaction.

Fat can undergo autolysis. An experiment that we carricd out in this connection may be mentioned. The fat near the kidney of a rabbit was removed aseptically; part of it was placed in a sterile tube, which was then hermetically sealed; another portion was placed in normal saline in a tube, which also was then hermetically sealed. The two tubes were kept at the temperature of $37^{\circ} \mathrm{C}$. for six weeks, and at the end of that time the contents were found to consist almost entirely of fatty acids and glycerine. Indications of a decomposition of the fat became visible to the naked eye at the end of six days.

A process similar to that observed in these experiments with test tubes appears to occur naturally in fat bodies free in the peritoneal cavity of an animal. For instance, in sereral cases that we have examined free fat bodies (detached appendices epiploicx) obtained from the peritoneal cavity of bovines showed fatty acid crystals in their central areas.

"It has been held by many observers that fat is absorbed by the intestinal epithelium in the form of an emulsion, and that the work of lipase is completed when enough fat has been decomposed to form the quantity of soap required to set up such an emulsion. Recent investigations have led many physiologists to question the accuracy of this view, and to hold that the fate of the great bulk of the fat is to be hydrolysed, and absorbed either as free fatty acid or as a soap." (Reynolds Green). ${ }^{3}$

With this latter view we are in accord, and we are further of opinion that the large masses of necrosed fat mentioned in the early part of this paper as having been found in the bodies of healthy bullocks simply represent a stage in the translocation of fat where the glycerine formed by the decomposition of the fat has been translocated more rapidly than the fatty acids produced at the same time. Just as sugar is the form in which the resting food material, starch, is translocated in plants after the action of the enzyme diastase; so apparently glycerine and fatty acids are the forms in which the resting food material, fat, is translocated in the animal body after the action of the enzyme lipase. If the fat is decomposed in situ more rapidly than it is translocated, then we shall have the appearance of necrosed fat, a similar but drier necrosed appearance being produced if the glycerine formed during the decomposition is removed before the fatty acids.

The view here enunciated receives support from the paper by J. B. Leathes ${ }^{4}$ on the Function of the Liver in Relation to the Metabolism of Fats, where he gives several grounds for believing

1 Quoted by C. E. SSimon, "Text-book of Physiological Chemistry," Second Edition, 1904, p. 196.

"Quoted by Reynolds Green, "The Soluble Ferments and Fermentations," 1899, p. 225.

3 Reynolds Green : Illcm, p. 224.

$\$$ J. B. Leathes: "Lancet," 27th February 1909. 
that the large amounts of fat found in the liver are often due to the importation of fat from the storage places in the connective tissue, and he emphasises the fact that that particular fat which is present in the connective tissue makes its appearance in the liver. He especially calls attention to the difference between organised and unorganised (i.e., resting) fat. The former is largely composed of phosphatide lipoid substances, our knowledge of which (with the exception of lecithin) is deficient. Clearly, the origin of these phosphatide lipoid substances is to be sought in the primary decomposition of the connective-tissue fat, by serum lipase, into glycerine and fatty acids. The case quoted by Sir James Paget, ${ }^{1}$ in which, during inanition, the fat of the connective tissue was absorbed but not the fat of a fatty tumour, does not militate against our view that fat metabolism in the body under the influence of lipase is to be represented by the reversible equation:

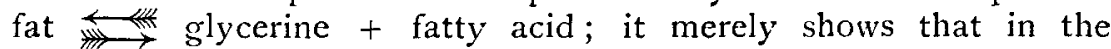
body of the individual noted the equation was not easily reversible, which perhaps accounts in part for the formation of the fatty tumours in the first place.

Two views may be advanced as to the cause of the presence of these masses of fatty acid crystals. Both views relate to the diminished vascular and lymphatic supplies of extensive masses of fat, such as occur round the kidneys and in the omentum of animals.

According to one, the animal, as a consequence of luxuriant natural feeding, has stored up such an excessive amount of fat that the central areas of this substance are to all intents and purposes cut off entirely from the circulatory system, and are in much the same state as the free fatty bodies mentioned as being sometimes found in the peritoneal cavity, or as the fat enclosed in the sealed test tubes already referred to. Under such conditions, presumably, the result would be autolysis of the cells whose lymph supply had been diminished almost to the vanishing point, with the consequent appearance of fatty acid crystals within the cells, and the liberation of glycerine. It is to be noted in support of this view that the animals in which the condition occurs seem always to be in excellent health and remarkably fat.

According to the other view, during some previous period in the life of a fat bullock a demand has been made by the tissues for fat ; the stimulus has reached the central areas of the various collections of fat, which by means of lipase have split up fat into fatty acids and glycerine. This having been accomplished, however, the poor vascular and lymphatic supplies of the more central portions of the fat masses have rendered it impossible for the fatty acids set free to pass into the general circulation. Better conditions for the animal then happening to occur, such as the passing away of a period of drought or the advent of much nutritious food, the demand of the tissues for fat has ceased and the process of storage of fat has again proceeded, now forming a deposit around the central masses of dissociated

1 Paget: "Lectures on Surgical Pathology," Third Edition, 1870, p. 378. Shattock ("Proceedings Royal Society of Medicine," Vol. II., Pathological Section, 1". 207) points out that this case quoted by fir James Paget is not beyond dispute. Of three oval swellings in the mesentery, one showed tuberculous lesions, though the two larger alparently consisted of soft yellow fat. 
fat, that is, in those parts of the adipose tissue better supplied with nutrient fluids. This would lead to a process of encapsulation of the dissociated fat; and the presence of the fatty acid crystals, acting as a foreign body, would result in the formation of a certain amount of fibrosis of the connective tissue in the neighbourhood.

In conclusion, it may be well to point out that these masses of fat dissociation have more than a mere scientific interest. It happened that one of us, in his own home, was recently carving a sirloin of beef when, in the midst of a mass of translucent half-melted yellow fat (peri-renal fat probably), a granular whitish material met his view. A tuberculous lesion round a lymph gland at once suggested itself as the nature of this pathological product, but closer inspection revealed the fact that it was merely a mass of fat dissociation rendered strikingly conspicuous by the greater transparency of the semi-molten normal fat. To the taste, the affected area had a slight gritty feel. Slices of the part were kept and preserved as museum specimens, one being placed in copper acctate solution first to bring out in detail the fat-dissociation area. An ordinary householder meeting such a tissue in the course of carving would probably jump at once to the conclusion that he had been served with meat from a tuberculous animal, and even part of the diseased tissue itself. Under such circumstances, the natural result would be the rejection of the sirloin from the table, with perhaps later an appeal to the medical officer of health, not to speak of unwarranted reflections on the butcher and on the authorities supervising the slaughter.

\section{PARALYSIS IN THE OSTRICH.}

By War. Robertson, M.R.C.V.S., Department of Agriculture, Cape Town.

VERY little is known about the diseases of the ostrich; in fact, if we exclude those caused by internal parasites, they are not even named, except by the owners of diseased birds, who employ designations suggested by the clinical symptoms. Thus, we have "dronkziekte," "kalkziekte," "kopziekte," and, of course, "lamziekte," this latter term being employed when a bird is down and unable to rise from any cause whatever.

The study of the diseases of the ostrich must be preceded by some study of the habits, nature, and constitution of the healthy bird, and, during this preliminary work, one is astonished to find how very little the best ostrich breeders do know about their charge's habits and behaviour; some of our most successful men will candidly admit that "when we farmed birds for five years we thought we knew all about them, but after fifteen we are forced to the conclusion that we have lots to learn."

It would appear that preconceived theorics are having to be modified, and, daily, new facts are being added to our knowledge. As I go on I find that our knowledge of the bird's habits is not so scanty, but is simply not distributed at all widely amongst the ostrich men.

Since the work of the late Hon. Arthur Douglas, I do not re- 